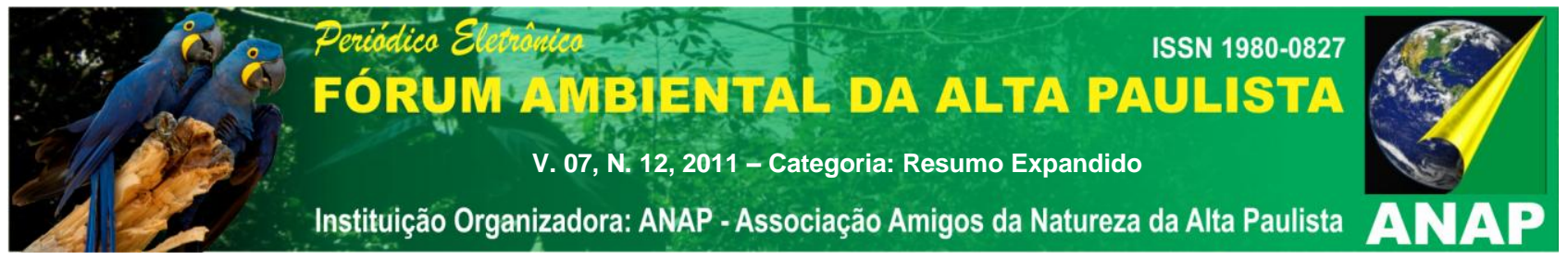

\title{
PROCAMALLANUS \\ (SPIROCAMALLANUS) \\ INOPINATUS \\ (NEMATODA: \\ CAMALLANIDAE) PARASITANDO ASTYANAX ALTIPARANAE GARUTTI \& BRITSKI, 2000 (CHARACIFORMES; CHARACIDAE) COLETADO NO RIO DO PEIXE, ESTADO DE SÃO PAULO, BRASIL.
}

Autora:

\section{Karina Gabriele Dias Alves}

Co-autores;

Talita Craveiro; Rodney Kozlowiski de Azevedo; Reinaldo José da Silva

Orientadora:

Vanessa Doro Abdallah Kozlowiski

Instituição:

Universidade Paulista Júlio de Mesquita Filho, Instituto de Biociências, Departamento de Parasitologia

E-mail:

vanessaabdallah@ig.com.br

Palavras-chave: Procamallanus (Spirocamallanus) inopinatus, Astyanax altiparanae, rio do peixe.

\section{INTRODUÇÃO}

O ambiente aquático é um meio no qual à penetração de agentes patogênicos torna-se facilitado. Desta forma o estudo dos agentes causadores de patologias nos peixes é um campo de crescente importância em virtude da expansão mundial da piscicultura, pois se sabe que estes, podem provocar elevadas taxas de mortalidade, redução das capturas ou 


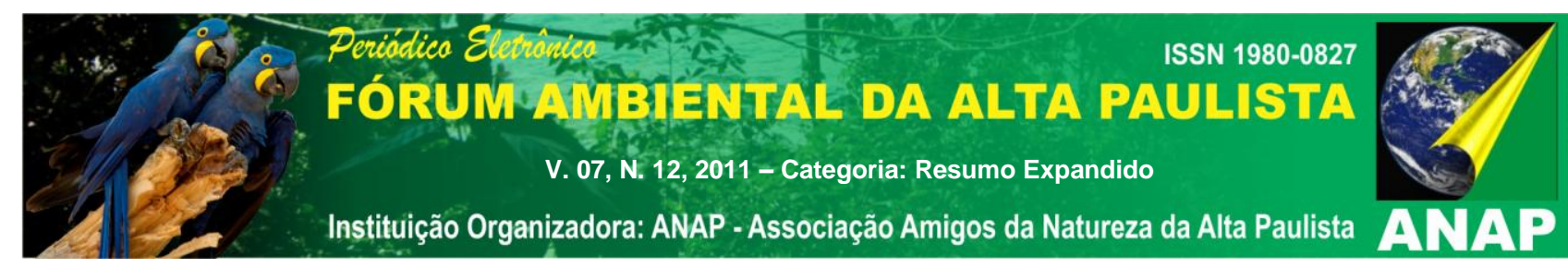

diminuição dos valores comerciais dos exemplares atacados (EIRAS, 1994). Nas últimas décadas tem aumentado consideravelmente a relevância dos estudos relacionados com parasitos e outros patógenos de organismos aquáticos, principalmente daqueles hospedeiros com potencial para o cultivo e comercialização, face ao aumento significativo destas atividades no Brasil e no mundo (LUQUE; POULIN, 2007).

O estudo da ecologia dos parasitos de peixes oferece informações importantes não só a respeito de seus hospedeiros, mas também do ambiente de maneira geral. A questão da importância da biodiversidade global tem sido muito discutida atualmente e alguns autores têm defendido o estudo das espécies de parasitos como parte fundamental desta, e como sendo o grupo menos estudado neste sentido, já que existe um déficit nos estudos sobre sistemática e biodiversidade parasitária no mundo (BROOKS; HOBERG, 2001, POULIN; MORAND, 2004). Esta biodiversidade, conseqüentemente, pode ser abordada, não apenas como uma questão de inventário de espécies, mas também como o estudo das relações hospedeiro-parasito em função de variáveis ecológicas e filogenéticas, visando detectar os determinantes da biodiversidade e sugerindo novas linhas de pesquisa neste sentido (POULIN; MORAND, 2004). Um aspecto importante em relação ao conhecimento da biodiversidade parasitária em peixes está relacionado com a geração de subsídios para a avaliação ambiental dos respectivos ecossistemas (ARAÚJO, 1997). Além disso, os parasitos são relativamente fáceis de serem identificados em situações críticas, como mortandade de seus hospedeiros, o que de forma geral, pode chamar a atenção para alterações nas condições dos ambientes aquáticos (KARR, 1981, KARR; DUDLEY, 1981). Os parasitos refletem, embora indiretamente, os hábitos de vida dos peixes, incluindo suas interações com as comunidades bentônicas, planctônicas e ícticas, podendo se constituir em indicadores do estresse ambiental tão sensíveis quanto o próprio hospedeiro.

O rio do Peixe tem suas nascentes localizadas no município de Torre de Pedra (SP) na região junto à Área de Preservação Ambiental (APA) da Cuesta Basáltica de Botucatu abrangendo uma sub-bacia de drenagem equivalente a $584,0 \mathrm{Km}^{2}$ no sentido do eixo SulNorte. Segundo Caramaschi (1986), trata-se de um rio que apresenta um forte gradiente 


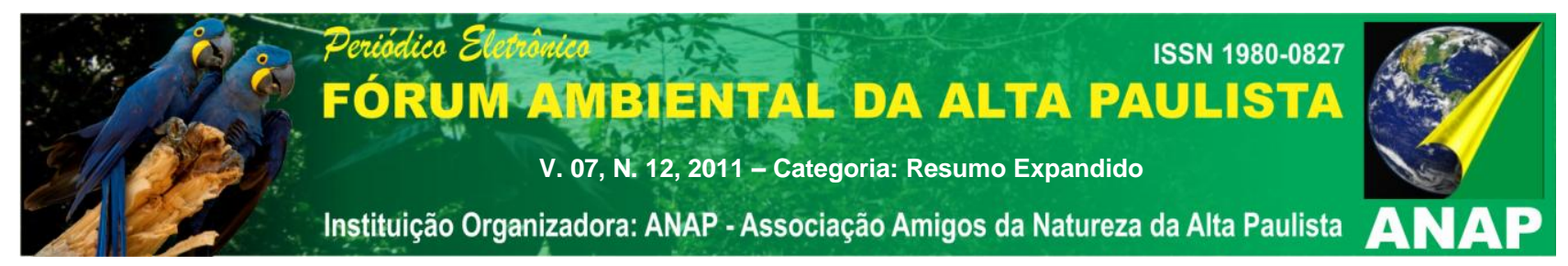

latitudinal com um desnível que inicia ao $700 \mathrm{~m}$ de altitude chegando à $430 \mathrm{~m}$ na sua desembocadura com a represa de Barra Bonita, no município de Anhembi (SP).

Nematóides parasitos constituem um dos primeiros grupos conhecidos de helmintos em peixes. Eles infectam peixes de água doce, marinhos e estuarinos e algumas espécies podem causar um prejuízo substancial aos seus hospedeiros. Embora os nematóides possam infectar quase todos os órgãos em peixes, a maioria das espécies atualmente conhecidas tem sido descritas no intestino. Muitos nematóides infectam peixes como adultos, mas uma grande proporção deles ocorrem como larvas. Estes são usualmente parasitos de aves piscívoras, mamíferos ou répteis, ou menos frequentemente peixes predadores. Estes vermes causam uma considerável perda econômica nas indústrias pesqueiras (Molnár et al., 2006).

\section{OBJETIVO GERAL}

O objetivo do presente projeto é obter um maior conhecimento da biodiversidade dos nematóides de Astyanax altiparanae Garutti \& Britski, 2000 do rio do Peixe e fazer um estudo taxonômico dos mesmos, em função da importância estratégica deste rio no Estado de São Paulo, gerando informações que possam futuramente servir como subsídios para estudos de integridade biótica da região.

\section{METODOLOGIA}

Quinze espécimes de $A$. altiparanae foram coletados. As coletas foram realizadas no rio do Peixe, com o auxílio de redes de espera. Após a coleta os peixes foram necropsiados, medidos e sexados. Cada órgão foi removido, lavado e peneirado com peneiras de $75 \mu \mathrm{m}$ de abertura. Os nematóides coletados foram fixados em álcool $70^{\circ} \mathrm{GL}$. No momento da identificação os espécimes foram montados em lactofenol. Os descritores ecológicos do parasitismo foram calculados segundo Bush et al. (1997). As fotografias foram realizadas em um microscópio com contraste de interferência diferencial (Leica DM 5000B).

\section{RESULTADOS}




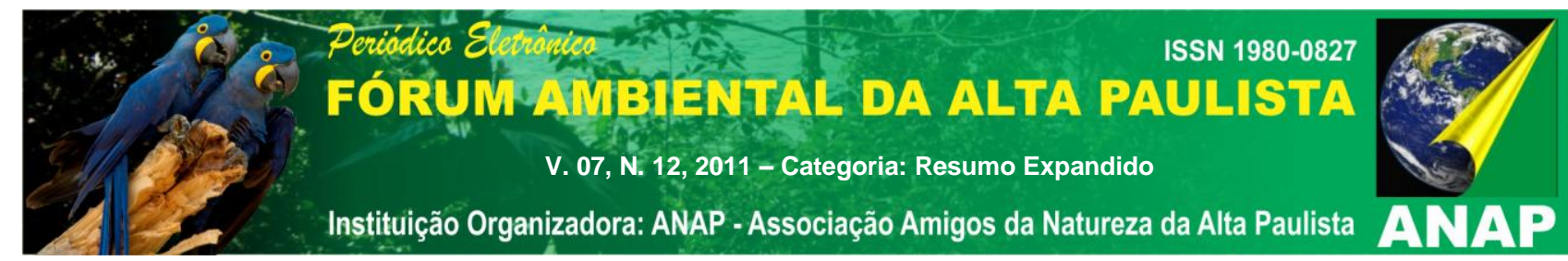

A espécie Procamallanus (Spirocamallanus) inopinatus foi encontrada parasitando o estômago e intestino de $A$. altiparanae, com uma prevalência de $73,3 \%$, intensidade média de 1,45 \pm 0,07 e abundância média de 1,06 $\pm 0,05$. O prejuízo causado pelos nematóides em peixes varia grandemente de acordo com a espécie presente, o órgão invadido e o número de vermes envolvidos (Molnár et al., 2006). A alta prevalência desta espécie de nematóide se explica porque esta espécie de peixe caracteriza-se como onívora, alimentando-se predominantemente de vegetais superiores, insetos e cepépodos, tendo preferência pela área de assoreamento, onde há grande quantidade de gramíneas e macrófitas aquáticas (onde se encontra grande quantidade de insetos e copépodos), sendo estes últimos os hospedeiros intermediários para os nematóides. Procamallanus (Spirocamallanus) inopinatus não é uma espécie tão específica, parasitando várias espécies de peixes, porém este é o primeiro registro em $A$. altiparanae.

\section{CONSIDERAÇÕES FINAIS}

Esta espécie está sendo registrada pela primeira vez neste hospedeiro e também pela primeira vez no rio do Peixe, expandindo assim a distribuição geográfica deste parasito.

\section{REFERÊNCIAS}

ARAÚJO, F. G. 1997. Adaptação do índice de Integridade Biótica usando a comunidade de peixes para o rio Paraíba do Sul. Rio de Janeiro. Revista Brasileira de Biologia 58: 547558.

BROOKS, D. R.; HOBERG, E. P. 2001. Parasite systematics in the 21st century: opportunities and obstacles. Trends in Parasitology 17: 273-275.

BUSH, A. O.; LAFFERTY, K. D.; LOTZ, J. M.; SHOSTAK, A. W. 1997. Parasitology meets ecology on its own terms: Margolis et al. revisited. Journal of Parasitology 83: 575-583.

CARAMASCHI, E. P. 1986. Distribuição da ictiofauna de riachos das Bacias do Tietê e do Paranapanema, junto ao divisor de águas (Botucatu, SP). Tese de Doutorado, UFSCar. EIRAS, J.C., 1994. Elementos de ictioparasitologia. Fundação Eng. António de Almeida, Portugal. 339p. 


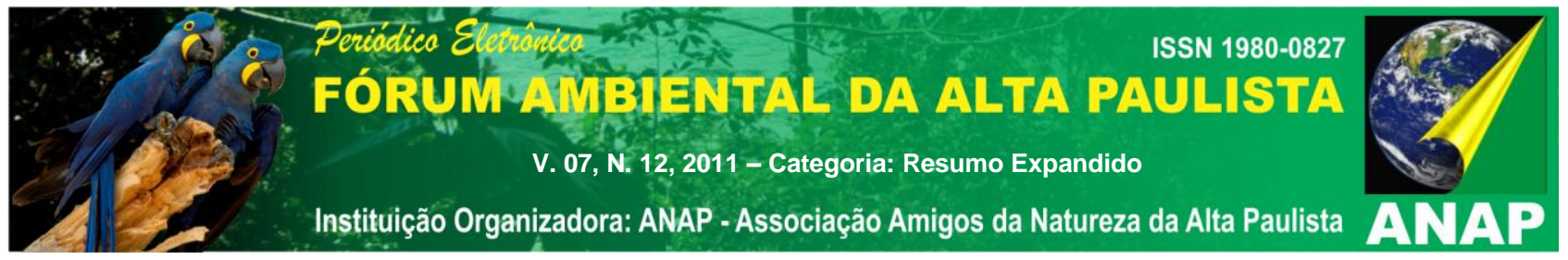

EIRAS, J. C.; TAKEMOTO, R. M.; PAVANELLI, G. C. 2006. Métodos de Estudo e Técnicas Laboratoriais em Parasitologia de Peixes. Maringá, EDUEM 2ª edição 199p.

KARR, J. R. 1981. Assessment of biotic integrity using fish communities. Fisheries 6: 21-27. KARR, J. R.; DUDLEY, D. R. 1981. Ecological perspective on water quality. Environmental Management 5:55-68.

LUQUE, J. L.; POULIN, R. 2007. Metazoan parasite species richness in Neotropical fishes: hotspots and the geography of biodiversity. Parasitology 134: 865-878.

MOLNÁR, K,; BUCHMANN, K; SZÉKELY, C. 2006. Phylum Nematoda. In: PTK WOO, (ed.) Fish Diseases and Disorders, Volume 1: Protozoan and Metazoan Infections. CABI Publishing, Canada.

POULIN, R.; MORAND, S. 2004. Parasite Biodiversity. Washington: Smithsonian Books, $216 p$. 